\title{
L. C. VS. PERÚ: LA BATALLA DE UNA NIÑA POR ACCEDER A LA JUSTICIA REPRODUCTIVA
}

L. C. Vs. Peru: the battle of a girl for accessing to reproductive justice

\author{
Brenda Ibette Álvarez Álvarez ${ }^{1}$
}

\section{RESUMEN}

En el presente artículo se aborda las restricciones y obstáculos en el goce del derecho a la interrupción legal del embarazo en casos de niñas víctimas de violencia sexual a partir de los estándares jurídicos del derecho internacional de los derechos humanos planteados en el caso L.C. vs. Perú del Comité para la Eliminación de la Discriminación Contra la Mujer (Cedaw). Asimismo, se plantea un análisis de los argumentos presentados por las representantes de la peticionaria, los descargos del Estado peruano y del razonamiento esgrimido por el Comité CEDAW en el caso.

PALABRAS CLAVES: Aborto - derechos humanos - derechos de las mujeres - estereotipos de género - discriminación - derechos sexuales y derechos reproductivos - autonomía reproductiva.

\begin{abstract}
This article addresses the restrictions and obstacles in the enjoyment of the right to legal interruption of pregnancy in cases of girls victims of sexual violence based on the legal standards of international human rights law raised in the L.C. vs. Peru of the Committee for the Elimination of Discrimination Against Women (Cedaw). Likewise, an analysis of the arguments presented by the petitioner's representatives, the Peruvian State's defense and the reasoning put forth by the CEDAW Committee in the case is presented.
\end{abstract}

KEY WORDS: Abortion - human rights women rights - genre stereotypes discrimination - sexual rights and reproductive rights - reproductive autonomy.

\footnotetext{
${ }^{1}$ Abogada con especialidad en Género, Derechos Humanos y Constitución por el Centro de Estudios Constitucionales, diplomada en Pluralismo Jurídico y Derecho Indígena y con estudios en la Maestría en Derecho Constitucional por la Pontificia Universidad Católica del Perú. Coordinadora del Área de Litigio Estratégico del Centro de Promoción y Defensa de los Derechos Sexuales y Reproductivos - Promsex. Abogada del caso ante el Comité CEDAW.
} 


\section{LA REGULACIÓN DEL ABORTO Y LA GARANTÍA DEL DERECHO A ACCEDER A LA INTERRUPCIÓN LEGAL DEL EMBARAZO EN EL PERÚ}

En el Derecho comparado existen tres sistemas de regulación del aborto: aquel que opta por la penalización total de aborto, el modelo de permisión por causales o indicaciones y el modelo de permisión por plazos (Ramírez y Alvarez, 2016). Según Siegel (2010, p. 189), los dos primeros modelos están cimentados en "estereotipos arcaicos de la mujer como 1) los estereotipos sobre la naturaleza, roles $\mathrm{y}$ capacidades de la mujer, 2) que niegan la decisión de la mujer y 3) con el supuesto propósito de protegerla de la coerción o liberarla para ser madre".

El modelo de regulación de indicaciones es el más extendido en Latinoamérica ${ }^{2}$. Este modelo establece excepciones a la penalización del aborto sea que la continuidad del embarazo suponga una afectación en el derecho a la vida y/o salud de la mujer, cuando el embarazo sea consecuencia de una violación sexual o cuando el feto es incompatible con la vida extrauterina. Este modelo, según Siegel, sigue la tradición de protección constitucional alemana, la misma que "ha tendido a incorporar visiones sobre la ciudadanía de las mujeres basadas en papeles de género convencionales, por ejemplo, que la carga del embarazo cae naturalmente en la mujer (...) excepto cuando la carga excede lo que puede esperarse normalmente de una mujer, momento en el cual se le exime de sanción penal por abortar su embarazo" (2016, p. 50).

Estas formas de regulación del aborto "excusan a la mujer de su deber de dar nacimiento al infante para proteger la supervivencia física de la mujer o proteger su bienestar físico y emocional" (Siegel, 2016, p. 51), mas no reconocen su derecho a la autonomía reproductiva, ya que la interrupción del embarazo en un primer momento está mediada por un hecho o circunstancia distinta a su decisión sobre la continuidad del embarazo.

En el Perú este es el modelo vigente desde 1924, siendo las únicas excepciones a la penalización del aborto aquellas en las que la continuidad del embarazo representan un riesgo a la vida o salud de la mujer ${ }^{3}$, excepción contenida en el artículo 119 del Código Penal. Manteniendo penalizados aquellos abortos cuyos embarazos son producto de violación sexual, aun cuando estos en sí mismos vulneren el derecho a la salud mental, y los

\footnotetext{
${ }^{2}$ A nivel jurisprudencial la Corte Constitucional de Colombia, a través de la sentencia C-355 de 2006, fue la primera instancia judicial en Latinoamérica en considerar constitucional tres causales aborto: cuando la vida o salud de la mujer se encuentra en riesgo, cuando el embarazo es producto de una violación sexual y cuando el producto de la gestación tiene malformaciones incompatibles con la vida extrauterina. Chile es el último país en incorporar este modelo a su regulación, añadiendo tres excepciones a la penalización del aborto a través de la aprobación y promulgación (14 de septiembre) del Boletín $N^{\circ}$ 9895-11 en el Congreso de la República de Chile, proyecto de ley que propone "regula la despenalización de la interrupción voluntaria del embarazo en tres causales" el mismo que incorpora modificaciones al artículo 119 del Código Sanitario autorizando la interrupción del embarazo cuando, mediando la decisión de la mujer a) la mujer se encuentre en riesgo vital, de modo que la interrupción del embarazo evite un peligro para su vida, b) el embrión o feto padezca una patología congénita adquirida o genética, incompatible con la vida extrauterina independiente, en todo caso de carácter letal, y 3) sea resultado de una violación, siempre que no hayan transcurrido más de doce semanas; en caso de niñas menores de 14 años, la interrupción se puede realizar siempre que el embarazo no sea mayor de catorce semanas de gestación. Cabe mencionar que este proyecto de ley fue puesto a conocimiento del Tribunal Constitucional de Chile para control constitucional y este, el 28 de agosto de 2017, fue declarado constitucional por esta instancia.

${ }^{3}$ Según el artículo 119 del Código Penal, no es punible el aborto practicado por un médico con el consentimiento de la mujer embarazada o de su representante legal, si lo tuviere, cuando es el único medio para salvar la vida de la gestante o para evitar en su salud un mal grave y permanente.
} 
embarazos de fetos cuya vida es incompatible con la vida extrauterina.

La despenalización del aborto tiene como correlato el reconocimiento del derecho de las mujeres a decidir sobre la continuidad del embarazo y el derecho de acceder a servicios médicos que garanticen la interrupción del embarazo de modo oportuno y seguro sea en un servicio público o privado. Esta atención de salud debe prestarse bajo el estándar del derecho a la salud, con el objetivo de prevenir daños, promover, conservar y/o restablecer la salud de las mujeres, bajo los siguientes parámetros: i) la disponibilidad, esta atención debe ser garantizada a nivel nacional; ii) accesibilidad, todas las mujeres que requieran esta atención deben poder acceder sin discriminación; iii) aceptabilidad, la atención debe garantizar la libre decisión de la mujer, el acceso a la información sobre el procedimiento y la confidencialidad; y iv) calidad, la atención debe prestarse bajo estándares de calidad del servicio conforme a los avances científicos (Comité de Derechos Económicos, Sociales y Culturales, 2000).

Sin embargo, la garantía del derecho al acceso al aborto legal en el Perú ha sido y sigue siendo un tema pendiente en la garantía del derecho a la salud de las niñas y mujeres. Una de las causas principales es la instalación de una "norma informal", esto es, el estereotipo de género sobre la maternidad forzada en las mujeres, que sugiere y sugirió que el aborto estaba totalmente prohibido independiente del artículo 119 del Código Penal (Bergallo, 2016). Consecuencias de esta norma han sido la ausencia de un protocolo sanitario que estandarice el procedimiento de aborto terapéutico, el desconocimiento del personal de salud respecto de sus funciones en la garantía del derecho a la interrupción legal del embarazo, la presencia estereotipos de género o la objeción de conciencia de funcionarios y prestadores del servicio que impiden que las mujeres accedan a servicios de aborto.

L. C. vs. Perú fue uno de los casos que puso en el debate público y jurídico la deficiencia del sistema sanitario en la garantía de este derecho fundamental, expuso las barreras con las que tienen que lidiar las niñas y mujeres cuyas vidas y salud se encuentran en riesgo para acceder a este derecho. A continuación, presentamos una síntesis de la ruta de litigio del caso, desde el embarazo forzado que tuvo que afrontar L. C. hasta las recomendaciones emitidas por el Comité CEDAW ${ }^{4}$.

\section{L. C., LA NIÑA QUE LUCHÓ POR SU VIDA Y EL DERECHO A DECIDIR DE LAS NIÑAS Y MUJERES ${ }^{5}$}

En el año 2007 L. C. era una niña de 13 años que vivía en el distrito de Ventanilla. Desde que tenía 11 años, era violada sexualmente por varios de sus vecinos. El 31 de marzo de ese año, L. C. se enteró de que, producto de dichos vejámenes, estaba embarazada. Horas después, se arrojó del techo de la casa contigua a la suya intentando acabar con su vida.

Sus familiares llamaron a los bomberos, quienes la llevaron a la posta médica de Ventanilla, pero debido a la gravedad de sus

${ }^{4}$ En adelante, el presente capítulo, al ser primordialmente una síntesis, recuento y análisis del caso L. C. vs. Perú ante el Comité CEDAW, se basa en los siguientes documentos: 1) la Comunicación ante el Comité de autoría del Centro de Derechos Reproductivos y del Centro de Promoción y Defensa de los Derechos Sexuales y Reproductivos presentada el día 18 de junio de 2009 ante el Comité CEDAW, y 2) el Dictamen en el que se declara admisible la comunicación y se pronuncia sobre el fondo (Comunicación CEDAW N²2/2009 del día 17 de octubre de 2011).

${ }^{5}$ Los hechos que en este apartado se relatan han sido extraídos de informes médicos y de oficios emitidos por el Hospital Nacional Daniel Alcides Carrión (HNDAC 2007a, 2007b, 2007c, y 2007d) y de la solicitud de intervención quirúrgica y aborto terapéutico para niña L. C., presentada el 18 de abril del 2007 por Teresa Palacios. 
lesiones, tuvo que ser referenciada al Hospital Daniel Alcides Carrión. L. C. no perdió la vida, pero sus lesiones en la columna fueron muy graves: traumatismo vertebro medular cervical y luxación cervical en las vértebras C6 y C7. Además de las lesiones físicas, la salud mental de L. C. también se encontraba comprometida, pues se le diagnosticó síndrome ansioso depresivo. El neurocirujano encargado de su atención indicó que, para resolver la lesión cervical, debía realizarse un procedimiento quirúrgico ${ }^{6}$.

La operación fue programada para el 13 de abril del mismo año. El día previo a la operación, el médico comunicó a Teresa Palacios, madre de L. C., que "no podía operar a su hija debido a que se encontraba embarazada"7. Teresa solicitó al médico, de modo verbal, la interrupción legal del embarazo; sin embargo, este le contestó que la decisión "no dependía de él, sino del departamento de Cirugía y de Asesoría Jurídica”.

La inacción de este médico no era un capricho personal: se ubicaba en el contexto de que el hospital no contaba con un procedimiento para hacer efectivas las solicitudes de interrupción legal del embarazo. Pese a ello, Teresa, como representante legal de L. C., solicitó el 18 de abril la interrupción legal del embarazo por causal terapéutica. En la solicitud se alegaba que la continuidad del embarazo representaba un riesgo para su salud física y un obstáculo para que la intervención de emergencia que su hija necesitaba se llevara a cabo. Esto sin contar que la continuidad del embarazo afectaba su salud mental, debido a los vejámenes vividos.
42 días después de la solicitud, la respuesta formal finalmente fue comunicada a Teresa. Para el director del hospital, el embarazo no podía ser interrumpido pues, según "la intervención de los jefes de departamentos involucrados en la atención de salud de la paciente, se concluye que la vida de la paciente no está en peligro como consecuencia del embarazo" (HNDAC 2007c:1). Es decir, se afirmaba que los diagnósticos médicos eran insuficientes para determinar que su vida y su salud se encontraban realmente amenazadas, por lo que el embarazo no podía ser interrumpido. Esta decisión fue apelada por Teresa y, el 27 de junio de 2007, cuando L. C. tenía 19 semanas de embarazo, el director del hospital dio respuesta a la solicitud de reconsideración, señalando que "las conclusiones arribadas por la junta médica que evaluó a L. C. no admite reconsideración ya que son decisiones tomadas por los diversos especialistas que la evaluaron" (HNDAC 2007d:1). El 11 de julio de 2007, L. C., casi tres meses y medio después de que se decidiera la necesidad de la operación y tras haber sufrido un aborto espontáneo, fue operada.

El 31 de julio, el informe médico correspondiente señalaba que L. C. requería terapia física, rehabilitación intensiva, atención psiquiátrica y psicológica. Dichas atenciones comenzaron recién 4 meses después: el 10 de diciembre de 2007. Debido a la dilación en la operación y en la atención de terapia física y rehabilitación, L. C. queda con cuadriplejía espástica. Esta condición se hace permanente debido a que tuvo que abandonar el tratamiento por falta de recursos económicos dado que las atenciones médicas no se encontraban cubiertas por el Estado.

\footnotetext{
${ }^{6}$ El médico Jaime Samaniego Zambrano, jefe del Servicio de Neurocirugía en el Informe Médico sobre el estado de salud de L.C refirió que "para resolver la lesión cervical se ha planteado: Artrodesis metálica por vía posterior con colocación de cable metálico de titanio (sistema Atlas), y poder brindar estabilidad a la columna vertebral" (HNDAC 2007a)

${ }^{7}$ La cita ha sido extraída de la solicitud de intervención quirúrgica y aborto terapéutico para niña L. C., presentada el 18 de abril del 2007 por Teresa Palacios.
} 
Desde ese año 2007, L. C. sobrevive con un cuadro de cuadriplejia espástica. Su vida cambió trágicamente. Actualmente, se encuentra paralizada desde el cuello para abajo $y$ solo ha recuperado parcialmente la movilidad de las manos. Depende de una silla de ruedas para moverse y de terceros para satisfacer todas sus necesidades. Se encuentra conectada a una sonda que le deben cambiar cinco veces al día en condiciones higiénicas de esterilización total, lo que le impide acudir a un centro de enseñanza. Con mucho esfuerzo y con el apoyo incondicional de su madre, a la edad de 22 años logró culminar sus estudios secundarios.

\section{L. C. VS. PERÚ ANTE EL COMITÉ CEDAW}

Ante la inexistencia de recursos adecuados y efectivos en sede interna que garanticen, por un lado, el acceso a un procedimiento disponible para solicitar la interrupción legal del embarazo como un protocolo médico, así como la no disponibilidad de recursos judiciales adecuados e idóneos para reclamar el derecho a acceder a la interrupción legal del embarazo el 18 de junio de 2009, el Centro de Promoción y Defensa de los Derechos Sexuales y Reproductivos - PROMSEX en conjunto con el Centro de Derechos Reproductivos presentaron una comunicación ante el Comité para la Eliminación de la Discriminación contra la Mujer (en adelante, el Comité CEDAW $)^{8}$ contra el Estado peruano por la vulneración de los derechos de L. C.

En la comunicación presentada ante el Comité se alegó al proceder del Estado la vulneración de los artículos 1, 2 (c) (f), 3, 5, 12 y 16 (e) de la Convención CEDAW, así como la Recomendación General N ${ }^{\circ} 24$ (en adelante, Recomendación General) del Comité por i) negarse a proveer la interrupción legal del embarazo y la intervención quirúrgica de la columna a L. C.; ii) permitir la discriminación en el acceso a tratamientos o intervenciones médicas que solo requieren las mujeres; iii) la ausencia de medidas que modifiquen prácticas discriminatorias hacia las mujeres que decidan por la interrupción legal del embarazo; y finalmente, iv) no contemplar mecanismos judiciales y administrativos que garanticen el acceso a una interrupción legal del embarazo. A continuación, se presenta una síntesis de los argumentos presentados ante el Comité.

\subsection{Agotamiento de recursos internos}

Al amparo de las excepciones al agotamiento de recursos internos contenidas en el artículo 4.1 del Protocolo Facultativo de la Convención sobre la Eliminación de Todas las Formas de Discriminación contra la Mujer, se alega la falta de mecanismos administrativos y judiciales que protejan a la mujer contra la discriminación en el acceso a la interrupción legal del embarazo en Perú.

En primer lugar, se evidenció un vacío legal, pues no existía ningún procedimiento o norma que regule el acceso al servicio médico del aborto terapéutico. Esto debido a que, con la Ley General de Salud vigente (aprobada el 9 de julio de 1997), fue derogado el Código Sanitario de 1981 que establecía el procedimiento sanitario para la interrupción del embarazo. Entonces, incluso cuando el aborto terapéutico era legal desde 1924, la práctica del mismo dependía finalmente de la discrecionalidad de los funcionarios de turno. En esta discrecionalidad intervinieron los juicios discriminatorios y prejuicios subjetivos de los funcionarios que, por lo general, se negaban a practicar y a autorizar la interrupción legal del embarazo.

\footnotetext{
${ }^{8}$ Se acude al Comité debido a que el Estado peruano ratificó la Convención para la Eliminación de Todas las Formas de Discriminación contra la Mujer, el 13 de septiembre de 1982, y su Protocolo Facultativo, el 9 de abril de 2001, a través del que reconoce la competencia del Comité para recibir comunicaciones frente a violaciones de los derechos que hacen parte de la Convención.
} 
En segundo lugar, en la comunicación se señala que el recurso de amparo no cumplía con el requisito temporal necesario para garantizar la vida y la salud de L. C. Esto pues, de acuerdo a los procedimientos que rigen este recurso, para contar con una decisión firme se requieren entre 62 y 102 días. Considerando que la primera negativa para realizar el aborto se dio en la $16^{\mathrm{a}}$ semana y la decisión firme y ejecutable se habría dado recién en la semana 28, que dejó la vida de L. C. incluso más comprometida.

En conclusión, al momento de los hechos, Perú no contaba con algún mecanismo administrativo o judicial capaz de asegurar la protección del derecho a una interrupción legal del embarazo de manera expedita.

\subsection{Los derechos vulnerados: igualdad $y$ no discriminación; a la vida y la vida en condiciones dignas; y de no ser sometido a tratos crueles, inhumanos y degradantes}

Alegamos que la negativa de proveer a L. C. un acceso oportuno a servicios médicos en la forma de la interrupción legal del embarazo y una intervención quirúrgica de la columna diagnosticada como inmediata vulneró sus derechos a estar libre de discriminación en el acceso a la salud y a no ser estereotipada dando prioridad a sus funciones reproductivas por sobre su bienestar (artículos 1, 2,3, 5 y 12 CEDAW y la recomendación general). Además, alegamos que el Estado vulneró otros derechos fundamentales y libertades esenciales como su derecho a la vida, a la vida digna y a estar libre de tratos crueles e inhumanos y degradantes en el contexto del acceso a servicios médicos sin discriminación.

Se alegó que la determinación del hospital de negar la interrupción legal del embarazo, además de tardía, injustificada y desproporcionada, fue ilegítima y arbitraria puesto que el Código Penal consideraba legal realizar un aborto cuando la salud de la mujer se encuentra en riesgo grave y permanente.

El condicionar el acceso a un tratamiento médico oportuno que solo requieren las mujeres y del que dependía su derecho a la salud, a la vida y a la vida en condiciones dignas a completar un embarazo involuntario resultó un tratamiento discriminatorio. Esto pues se basó en el estereotipo de imponerle a L. C. su función reproductiva por encima de su bienestar. Según los hechos, la continuidad del embarazo de L. C. sí constituía una amenaza para su salud física y mental, lo que hacía procedente y necesaria la interrupción legal del embarazo. De haberse realizado oportunamente este procedimiento, L. C. habría podido acceder a la intervención médica (operación de columna) que representaba la única esperanza de mejoría en su salud física y mental y en su calidad de vida.

Con relación a la vulneración de otros derechos fundamentales como su derecho a la vida y a la vida en condiciones dignas, se sostuvo que la demora en la intervención quirúrgica redujo las posibilidades de mejoría de L. C., pues como resultado de ello se encuentra paralizada desde el cuello para abajo, depende de una silla de ruedas para moverse y de terceros para satisfacer todas sus necesidades. Así, la inmovilidad y dependencia que han truncado irreversiblemente su proyecto de vida son producto de una barrera discrecional $\mathrm{y}$ arbitraria en el acceso a un servicio legal.

Respecto a la vulneración de otros derechos fundamentales como el no ser sometido a tratos crueles, inhumanos y degradantes las representantes de la niña sostuvieron que someter a una niña durante 42 días a esperar 
una determinación sobre el destino de su salud y sobre la posibilidad de su recuperación constituyó un trato cruel e inhumano. Igualmente, imponer a una mujer llevar a término un embarazo indeseado es equivalente a la tortura, pues L. C. no quería ser madre y se encontraba legítimamente autorizada, con la compañía de su madre, para decidir interrumpir ese embarazo. Asimismo, se señaló que el trato inhumano y degradante también se configuró en la espera de casi tres meses y medio para la realización de la operación a la columna.

\subsection{La negativa de proveer la interrupción del embarazo y el derecho a decidir el número de hijos y el espaciamiento entre estos}

A pesar de que el Perú tiene la obligación de abstenerse de interferir de manera arbitraria en las decisiones de la vida privada de las personas (como es el ámbito reproductivo), así de garantizar el efectivo respeto de las decisiones que se refieren a esta esfera, en el caso de L. C., los prestadores del servicio de salud tomaron una decisión acerca de su cuerpo y su salud, entrometiéndose en la esfera privada de forma ilegítima, vulnerando así su derecho a determinar el número de hijos y el espaciamiento entre los mismos.

Por ello, alegamos que la determinación de los médicos de no realizar el aborto, contra la voluntad de L. C., constituía una injerencia arbitraria en la toma de decisiones sobre su reproducción e implicaba la violación del artículo 16 e) de la CEDAW.

\subsection{La omisión del Estado de modificar normas o prácticas discriminatorias que limiten el goce del derecho a acceder a un aborto terapéutico}

Alegamos que adoptar medidas legislativas regulatorias, administrativas o judiciales que protejan y aseguren el derecho al acceso a la salud en condiciones de igualdad en el contexto del aborto terapéutico es una obligación del Estado de aplicación inmediata. La ausencia de dicho marco jurídico regulatorio, evidenciada en el caso de L. C. en prácticas de discriminación en el acceso y calidad del servicio médico, constituye una infracción de las obligaciones internacionales adquiridas por el Perú contenidas en los artículos 2 (f), 3 y 5 de la CEDAW, en relación con los artículos 12 y 16 de la Convención CEDAW, así como la Recomendación General $\mathrm{N}^{\circ} 24$.

La falta de esas medidas se tradujo en una situación de absoluta discrecionalidad, en la que los profesionales de la salud pudieron denegar a L. C. servicios médicos oportunos de manera desproporcionada e ilegal. Finalmente, la vulneración de los derechos de L. C., protegidos por la Convención, se vio acrecentada por la condición de la víctima de ser niña y con escasos recursos económicos.

\section{LA DEFENSA DEL ESTADO PERUANO: PERSISTENCIA EN LA DISCRIMINACION}

La defensa del Estado peruano frente a lo alegado estuvo direccionada a i) atribuir responsabilidad a L. C. y su familia de la afectación a su salud y vida; ii) desestimar los argumentos sobre la falta de garantía en la atención en salud de L. C. negando su responsabilidad; iii) argumentar que el Estado ofreció todos los servicios y recursos efectivos a L. C. para la evaluación de la viabilidad de la interrupción legal del embarazo; y, iv) argüir la falta de agotamiento de vías previas como el proceso constitucional de amparo y la vía civil indemnizatoria. Es decir, el Estado enfatizó en el desconocimiento de las pretensiones de fondo planteado en la comunicación e insistió con argumentos discriminadores como atribuir 
a L. C. la responsabilidad de las lesiones sufridas por la tentativa de suicidio.

En el siguiente cuadro, mostramos los principales argumentos de la defensa sostenida por el Estado, así como los comentarios que planteamos a dichos argumentos.

\begin{tabular}{|c|c|c|}
\hline $\begin{array}{l}\text { Puntos en } \\
\text { discusión }\end{array}$ & $\begin{array}{c}\text { ESTADO PERUANO } \\
\text { Comentarios sobre el fondo, } 20 \text { de } \\
\text { enero de } 2010\end{array}$ & $\begin{array}{c}\text { PETICIONARIAS } \\
\text { Comentarios a las observaciones del } \\
\text { Estado, } 15 \text { de abril de } 2010\end{array}$ \\
\hline $\begin{array}{l}\text { La } \\
\text { responsabilidad } \\
\text { de los hechos }\end{array}$ & $\begin{array}{l}\text { Hay responsabilidad de L. C. } \\
\text { y su familia por no haber } \\
\text { buscado el apoyo que habría } \\
\text { permitido realizar un } \\
\text { tratamiento frente al abuso } \\
\text { sexual del que fue objeto. }\end{array}$ & $\begin{array}{l}\text { Rechaza la atribución de } \\
\text { responsabilidad a L. C. y su } \\
\text { familia. Culpar a una menor por } \\
\text { hechos que escapan totalmente de } \\
\text { su control (como haber sufrido } \\
\text { abusos sexuales) es cruel y revela } \\
\text { una actitud discriminatoria. }\end{array}$ \\
\hline $\begin{array}{l}\text { La denegación } \\
\text { de la cirugía de } \\
\text { columna }\end{array}$ & $\begin{array}{l}\text { - El estado de salud de L. C. no } \\
\text { empeoró necesariamente por no } \\
\text { haberle practicado la cirugía. } \\
\text { - La operación quirúrgica de la } \\
\text { columna no se podía dar hasta } \\
\text { que no hubiese mejorado la } \\
\text { herida colindante a la zona de la } \\
\text { incisión quirúrgica. }\end{array}$ & $\begin{array}{l}\text { - Desde su primer diagnóstico, los } \\
\text { informes médicos constataron el riesgo } \\
\text { de discapacidad permanente y de } \\
\text { deterioro de la integridad cutánea } \\
\text { resultante de la inmovilidad física. } \\
\text { - La nota de evolución de } 12 \text { de abril } \\
\text { señala que la única causa del } \\
\text { aplazamiento fue la prevención de daño } \\
\text { al feto. No fue la infección cutánea lo } \\
\text { que motivó postergar la cirugía. }\end{array}$ \\
\hline $\begin{array}{l}\text { La prestación } \\
\text { de servicio } \\
\text { médico }\end{array}$ & $\begin{array}{l}\text { - L. C. recibió atención médica } \\
\text { inmediata y se le practicaron } \\
\text { diversos exámenes médicos, } \\
\text { incluidos los de psiquiatría y } \\
\text { neuropsicología. }\end{array}$ & $\begin{array}{l}\text { - La cirugía que L. C. requería tenía } \\
\text { carácter de urgente y no electivo. La } \\
\text { dilación de esta cirugía reduce la } \\
\text { capacidad de recuperación del paciente. } \\
\text { - La restricción del acceso al servicio de } \\
\text { salud estuvo basada en estereotipos de } \\
\text { género que entienden el ejercicio de la } \\
\text { capacidad reproductiva de la mujer } \\
\text { como un deber y no como un derecho. }\end{array}$ \\
\hline $\begin{array}{l}\text { La solicitud de } \\
\text { aborto } \\
\text { terapéutico }\end{array}$ & $\begin{array}{l}\text { - Aunque el resultado de la } \\
\text { solicitud de L. C. no haya sido el } \\
\text { esperado por ella, lo cierto es que } \\
\text { sí tuvo la posibilidad de recurrir a } \\
\text { las autoridades competentes. }\end{array}$ & $\begin{array}{l}\text { - En el análisis de la intervención } \\
\text { médica, las posibilidades de que este } \\
\text { produjera daño en el feto fueron } \\
\text { antepuestas a las posibilidades de } \\
\text { rehabilitación de L. C. } \\
\text { - Al no existir regulaciones para el } \\
\text { acceso al aborto terapéutico, los } \\
\text { requisitos, plazos, procedimientos y la } \\
\text { valoración de la opinión de la mujer en } \\
\text { el acceso a este dependen de la } \\
\text { discrecionalidad de cada hospital. }\end{array}$ \\
\hline
\end{tabular}




\begin{tabular}{c|c}
$\begin{array}{c}\text { El derecho a } \\
\text { decidir sobre la }\end{array}$ & -No se puede hablar de un \\
capacidad & "derecho" a decidir, pues la \\
reproductiva & posibilidad de aborto terapéutico \\
cuando la vida & gestante, sino que depende de los \\
o la salud \\
corren riesgo
\end{tabular}

- La voluntad de la mujer es fundamental: determinar la gravedad del daño que la continuación del embarazo puede causar tiene un componente subjetivo (el nivel de riesgo que la mujer está dispuesta a soportar) que no puede ser ignorado.

- La falta de regulación en el acceso al aborto terapéutico constituyó una violación a su derecho al sujetarla a la arbitrariedad de los agentes del Estado.

\section{PRONUNCIAMIENTO DEL COMITE CEDAW}

El 17 de octubre de 2011, el Comité CEDAW aprueba la Comunicación $\mathrm{N}^{\circ}$ 22/2009, Dictamen en el que se declara admisible la comunicación y se pronuncia sobre el fondo. El Comité determinó que el Estado peruano es internacionalmente responsable

por haber vulnerado los artículos 1, 2 (c) (f), 3, 5, y 12 de la Convención CEDAW.

\subsection{Sobre la admisibilidad de la comunicación}

El Comité consideró que, dada la gravedad del estado de salud de L. C., ella no tuvo a su disposición ningún recurso administrativo $\mathrm{y}$ judicial efectivo. Exigir a L. C. acudir a las instancias judiciales, a criterio del Comité, no superaba el estándar de razonabilidad e idoneidad debido a la vaguedad de los plazos y la celeridad del proceso de amparo. En consecuencia, concluyó que la excepción del agotamiento de los recursos de la jurisdicción interna prevista en el artículo 4 , párrafo 1 , del Protocolo Facultativo, relativa a la improbabilidad de que el recurso de amparo brindara un remedio efectivo a la víctima, era aplicable.

El Comité determinó los siguientes hechos indiscutidos (CEDAW, 2011, p. 14-15):
- "L. C. fue hospitalizada el 31 de marzo de 2007;

- el Jefe del Departamento de Neurocirugía recomendó una intervención quirúrgica, que se programó para el 12 de abril de 2007; en la fecha prevista la intervención fue cancelada;

- el 13 de abril de 2007, el Jefe del Departamento de Neurocirugía comunicó a la autora que no podía operarse a L. C. en razón de su embarazo,

- el 18 de abril de 2007, la autora envió una solicitud por escrito a las autoridades médicas para que se interrumpiera el embarazo.

- La Junta Médica del hospital no tomó una decisión sobre la solicitud hasta el 30 de mayo de 2007.

- El 7 de junio de 2007, la autora, basándose en un informe del Colegio Médico del Perú de fecha 7 de mayo de 2007, según el cual la continuación del embarazo acarrearía graves riesgos para la salud de L. C., presentó un recurso ante las autoridades del hospital para que reconsideraran su decisión.

- No se tomó una decisión al respecto hasta el 27 de junio de 2007, siendo así que L. C. había abortado espontáneamente el 16 del mismo mes de junio. En la decisión se indicaba que era inapelable". 


\subsection{Sobre el fondo}

A partir de su análisis sustantivo sobre el fondo, el Comité consideró lo siguiente (CEDAW, 2011, p.15-18):

- Que hubo "una relación directa entre el retraso de la operación quirúrgica, cuya necesidad no puede ser puesta en duda, y la continuidad del embarazo de L. C."

- Que el aplazamiento de la intervención quirúrgica respondió al estereotipo de género 9 de "anteponer la función reproductiva de L. C. a su derecho a la salud, la vida y la vida en condiciones dignas".

- Que el acceso a servicios médicos no puede verse limitado por la presencia de estereotipos de género. Así, "la negativa de un Estado parte a prever la prestación de determinados servicios de salud reproductiva a la mujer en condiciones legales resulta discriminatoria"

- Que la Ley General de Salud del Perú que derogó el procedimiento para el aborto terapéutico "creó un vacío jurídico, porque no previó ningún procedimiento para solicitar la interrupción legal del embarazo".

- Que, "debido a su condición de mujer embarazada, L. C. no tuvo acceso a un procedimiento sanitario y judicial eficaz que le permitiese acceder a su derecho a los servicios de atención médica que su estado de salud física y mental requería".

- Que el Estado fue responsable de no valorar de modo adecuado, en las deliberaciones de las juntas médicas para la procedencia del aborto terapéutico, el riesgo a la salud física y mental que los hechos representaban para $L$. C. "La tardanza de las autoridades hospitalarias en resolver la solicitud tuvo consecuencias nefastas para la salud física y mental de L. C."

- Que el hecho de que el Estado peruano mantuviera la penalización del aborto por violación "contribuyó a la situación en que se encuentra L. C."

- Que el daño generado a L. C. se extendió a su familia, principalmente a su madre, debido a que la familia de L. C. sufrió graves daños morales y materiales a raíz de los daños ocasionados a L. C.

Es decir, para el Comité resultó incuestionable que la intervención quirúrgica de L. C. era necesaria y que el acceso a esta le fue negada en base a estereotipos de género. Además, estableció que, dado el vacío jurídico sobre el aborto terapéutico, L. C. no tuvo acceso a procedimientos eficaces para acceder a sus derechos. En ese sentido, el Estado fue responsable de no valorar el riesgo a la salud física y mental que, finalmente, conllevó a graves daños morales y materiales a L. C. y su familia. Finalmente, que a estos daños también contribuyó la penalización del aborto por violación.

\subsection{Recomendaciones del Comité}

El Comité recomendó al Estado peruano que adopte medidas de reparación para L. C. que comprenda indemnización y medidas de rehabilitación en proporción a la gravedad de la violación de sus derechos.

Como medidas de no repetición, el Comité recomendó al Estado lo siguiente:

i. Establecer un mecanismo para el acceso efectivo al aborto terapéutico que garantice el derecho a la salud física y mental de las mujeres

ii. Tomar medidas para las disposiciones pertinentes de la Convención y la

\footnotetext{
"“Los estereotipos de género hacen referencia a una preconcepción de atributos o características poseídas o papeles que son o deberían ser ejecutados por hombres y mujeres, respectivamente". Véase en Corte Interamericana de Derechos Humanos, caso González y otras ("Campo Algodonero") vs. México. Excepción Preliminar, Fondo, Reparaciones y Costas. Sentencia de 16 de septiembre de 2009, párr. 401.
} 
Recomendación General $\mathrm{N}^{\circ} 24$ en relación con la garantía de los derechos reproductivos en los centros de salud

iii. Despenalizar el aborto cuando el embarazo tenga como causa una violación o un abuso sexual.

Finalmente, el Comité instó al Estado a revisar la interpretación restrictiva del aborto terapéutico de conformidad con la Recomendación General, además de publicar el dictamen y las recomendaciones del Comité.

\section{COMENTARIOS FINALES}

El Comité CEDAW, en el caso L. C. vs. Perú, fijó estándares jurídicos paradigmáticos sobre el derecho a la autonomía reproductiva de las mujeres y el derecho a la salud libre de estereotipos de género sobre la maternidad. Asimismo, ha impulsado la aprobación de la Guía técnica de interrupción voluntaria del embarazo por razones terapéuticas.

Sin embargo, hay aspectos que de haber sido abordados con mayor énfasis tanto en nuestra estrategia de litigo como por el Comité; habrían contribuido a fortalecer el enfoque diferencial en el análisis del caso, en la determinación de la responsabilidad internacional del Estado, los estándares jurídicos fijados y en la especificidad de las reparaciones individuales y generales.

Uno de ellos que, aunque fuera planteado en nuestra comunicación al Comité, fue el enfoque de niñez y la obligación del Estado de garantizar protección reforzada en el acceso a la atención médica para la interrupción legal del embarazo cuando se trate de niñas. Pues si bien a todas las mujeres cuya vida o salud se ponga en riesgo por la continuidad de un embarazo se les debe garantizar acceso a servicios oportunos de aborto, lo cierto es que, en el caso de niñas, dadas las condiciones especiales en las que se encuentran (dependencia económica, indefensión, vulnerabilidad, entre otros), se hace necesario la adopción de medidas específicas con el objetivo de proveer el acceso a servicios de salud en contextos de igualdad y calidad.

Esto nos llama a pensar en atenciones diferenciadas destinadas, especialmente, a: la consejería, la celeridad en la tramitación de las solicitudes de interrupción del embarazo, el derecho a decidir con respecto a la maternidad, la primacía del consentimiento de las niñas por sobre la de su padre o madre/tutor(a) o la decisión de los representantes del Ministerio Público en ausencia de sus representantes, la atención especializada de personal médico debidamente capacitado para la atención de niñas víctimas de violencia sexual, la protección de su identidad en el trámite de la solicitud, entre otros aspectos.

El Comité también omitió analizar la condición de discapacidad de L.C., en la que ya se encontraba cuando se le niega la interrupción del embarazo, en la determinación de la responsabilidad internacional del Estado, la intensidad de la violación de derechos de la niña y la fijación de las reparaciones. Esto a la luz de la obligación reforzada de los servicios de salud frente al riesgo de agravar la discapacidad.

Esto se ve traducido en la recomendación general de establecer un mecanismo para el acceso efectivo al aborto terapéutico, esta no hace referencia a las características específicas de este procedimiento en caso de niñas y personas en situación de discapacidad. En definitiva, el enfoque de intersecciones de las discriminaciones hubiera contribuido delinear un estándar especializado para el acceso al aborto legal en el caso de niñas. 


\section{REFERENCIAS BIBLIOGRÁFICAS}

-Bergallo, P. (2016). La lucha contra las normas informales que regulaban el aborto en Argentina. En R. Cook y otros. El aborto en el derecho transnacional. Casos y controversias. México: Fondo de Cultura Económica, 119.

-Centro de Derechos Reproductivos y Centro de Promoción y Defensa de los Derechos Sexuales y Reproductivos (2009). Comunicación al

Comité para la Eliminación de la Discriminación contra la Mujer bajo el protocolo opcional de la Convención para la Eliminación de todas las formas de discriminación contra la mujer.

-Comité CEDAW (1999). Recomendación General No. 24 (Artículo 12): La Mujer y la Salud, Doc. de la ONU A/54/38/Rev.1

-Comité CEDAW (2011). L. C. c. Perú, Comunicación No 22/2009, Doc. de la ONU CEDAW/C/50/D/22/2009

-Comité de Derechos Económicos, Sociales y Culturales. (2000). Observación General $N^{\circ} 14$. El derecho al disfrute del más alto nivel posible de salud. Recuperado de:

http://www.acnur.org/t3/fileadmin/Documentos/ BDL/2001/1451.pdf.
-Hospital Nacional Daniel Alcides Carrión (HNDAC) :

- (2007a). Informe Médico elaborado por el Jefe de Servicio de Neurocirugía. 24 de mayo de 2007.

- (2007b) Informe neuropsicológico elaborado por el psicólogo Daniel Herrera y la interna Carmen Suazo.2 de mayo de 2007.

- (2007c). Oficio $\mathrm{N}^{\circ}$ 2495-2007-DG-HNDAC-C, respuesta a la solicitud de interrupción legal del embarazo. 30 de mayo de 2007.

- (2007d). Oficio $\mathrm{N}^{\circ}$ 2496-2007-OAJHN.DAC, respuesta a la solicitud de reconsideración a la opinión de la junta médica sobre la interrupción de la gestación de L. C. 27 de junio de 2007.

- Ramírez, B. y Álvarez, B. (2016). Derecho y aborto: reforma normativa sobre su despenalización y acceso por litigio estratégico en el Perú. Revista de Derecho Forseti. Lima. 